\title{
The impact of health information systems on the performance of human resources (HR) in King Faisal Specialist Hospital in Taif
}

\author{
Dr. Adnan Awad Shawabkeh \\ College of Business \\ Department of Management Information Systems \\ Taif University
}

\begin{abstract}
This study aimed at identifying the impact of health information systems on the performance of human resources (HR) in King Faisal Specialist Hospital in Taif. In order to achieve the objectives of the study, a questionnaire was designed and developed for the purpose of collecting data and distributing it among the 72 sample members. The Statistical Package for Social Sciences (SPSS) was used to analyze the data. The descriptive statistical methods were used to test the hypotheses. The study concluded a number of results, the most important are: -
\end{abstract}

1. That respondents' perceptions of the requirements of health information systems were high.

2. That respondents' perceptions of the performance of human resources (HR) were high.

3. The requirements of health information systems (hardware, software, human and organizational) have an impact on the performance of human resources.

4. There are no statistically significant differences due to the variables of (age, qualification and professional experience).

The study recommended the following :

1. Activating the concept of human relations between senior management and employees in order to enhance the motivation of employees and improve their performance.

2. Designating the right man in the right place in proportion to their abilities and study qualifications, thus increasing their acceptance of work and improving performance leading to not overburdening them with wok beyond their capabilities and the time required for completion.

3. Increasing the support of the senior management to the users of the system and polling their views on the problems they face in order to overcome such problems.

4. Providing software that is compatible with the devices and networks being used.

\section{INTRODUCTION}

Health care is the core of the prevailing health system in many countries around the world due to many considerations, especially the development plans and their various programs, which depend on the availability of a workforce empowered with health and high efficiency. The productivity of the individual is partially realized when welfare prevails society as a whole in its broader sense. The integrated health system therefore means an effective development system for which people aspire to growth and progress in medical aspects through spending on infrastructure and related services (Mosleh, 2012).

In the 1940s, computers were developed. The whole community realized that these devices would provide mankind with many services, especially in the field of information, storage, processing and retrieval. Doctors and specialists have attempted to take advantage of such 
technologies in real life by developing the idea information management and the role of computers in medicine and health care. One of the most important developments was the idea of electronic medical records, which represent the nerve of information related to the provision of health care to the patient. The stages of the process of improving the medical records and their integration with different information sources, through information network systems, have led to the idea of decentralization and communication of information between more than one hospital and a medical institution, and even more through the Internet, which has enabled millions of users to rely on it as a source for the search for medical information (Wager et al., 2005).

The performance of human resources is the core of administrative development, through which the employee's performance is monitored and his functional abilities are improved so as to make performance results consistent with the objectives of the organization, and enable the employee to carry out his duties, develop his abilities to assume additional responsibilities that achieve a high degree of job satisfaction, and adapt to the work environment (Al-Qurashi, 2007).

\section{Problem of the study :-}

The researcher's knowledge of the health services at King Faisal Hospital shows that the health information systems currently in use have an impact on the medical and administrative fields in terms of preparing statistical reports related to the work and the transfer of laboratory results from different departments and all operations related to the patient's record. Nevertheless, the system does not process medical orders electronically and does not provide all the information for patients in an integrated manner, and the system does not allow to completely dispense with the medical paper record as well, therefore; there is a relationship between health information and the performance of human resources thus leading to forming the problem of the study through the following main question :-

What is the impact of health information systems on the performance of human resources (HR) in King Faisal Specialist Hospital in Taif?

\section{Study questions : -}

1. The availability of health information systems requirements (HR) at King Faisal Specialist Hospital?

2. Is there an impact on the use of health information systems on the performance of human resources (HR)?

3. What is the level of implementing health information systems in King Faisal Specialist Hospital?

4. What is the level of performance of human resources in King Faisal Specialist Hospital?

\section{Objectives of the study: The study aims to achieve the following :-}

1. Identifying the availability of health information systems requirements (hardware, software, human and organizational requirements).

2. Identifying the level and extent of the use of health information systems in their four dimensions and their impact on the performance of human resources.

3. Knowing the role played by health information systems and their impact on the performance of human resources.

4. Identifying the relationship between the implementation of health information systems in its four dimensions on the performance of human resources.

5. Identifying the level of performance of human resources. 


\section{The importance of the study : The importance of the study is highlighted through the} following points :-

1. The need to pay attention to users at King Faisal Specialist Hospital in Taif.

2. King Faisal Hospital is considered one of the most important sectors providing direct health services to citizens.

3. Assisting the decision makers in King Faisal Hospital and identifying the strengths and weaknesses of the system used.

4. According to the researcher, there are few Arabic studies that examined the issue of health information systems in the organizations.

5. Assisting in theoretical enrichment and providing all new information in the field of health information systems, which is regarded one of the most important issues in the field of management, and providing it to researchers and scholars in this field.

\section{The First Main Hypothesis :-}

\section{STUDY HYPOTHESES}

There was no statistically significant effect at the level of $\alpha \leq 0.05$ for the use of health information systems (hardware, software, human and organizational requirements) on the performance of human resources at King Faisal Specialist Hospital in Taif.

\section{The first sub-hypothesis :-}

There was no statistically significant effect at the level of $\alpha \leq 0.05$ for the hardware requirements of health information systems on the performance of human resources at King Faisal Specialist Hospital in Taif.

\section{The second sub-hypothesis :-}

There was no statistically significant effect at the level of $\alpha \leq 0.05$ for the software requirements of health information systems on the performance of human resources in King Faisal Specialist Hospital in Taif.

\section{The third sub-hypothesis :-}

There was no statistically significant effect at the level of $\alpha \leq 0.05$ for the human requirements of health information systems on the performance of human resources in King Faisal Specialist Hospital in Taif.

\section{The fourth sub-hypothesis :-}

There was no statistically significant effect at the level of $\alpha \leq 0.05$ for the organizational requirements of health information systems on the performance of human resources in King Faisal Specialist Hospital in Taif.

\section{The Second Main Hypothesis :-}

There are no statistically significant differences at the level of $\alpha \leq 0.05$ for health information systems in improving the performance of human resources in King Faisal Hospital due to the personal and professional variables of variables (age, qualification and professional experience).

\section{METHODOLOGY AND PROCEDURES}

The descriptive, analytical and field research methodology was adopted. A desk survey was conducted to examine the theoretical and field studies and research in the field of management information systems in order to crystallize the foundations and principles of the theoretical framework. The concept of computerized health information systems and the importance of 
their employment in public hospitals in the Kingdom of Saudi Arabia in general and in Taif in particular will be made clear.

As for the analytical field research is concerned, a sample of the study population has been surveyed asking them to answer the questionnaires that were designed for this study. The collected data were analyzed by means of statistical methods using the Statistical Package for Social Sciences (SPSS). After analyzing the data and inferring the preliminary results, the hypotheses of the study were tested using the appropriate statistical methods and the results were deducted.

\section{The study population : -}

The study population consists of 170 employees at King Faisal Hospital in Taif Governorate.

\section{The study sample :-}

King Faisal Specialist Hospital in Taif is considered one of the most important sectors that provide medical and health services to the public. A total of 85 samples of the study population were selected, where 80 questionnaires were retrieved at $94.11 \%$. Eight questionnaires were not considered serious when being filled out. Thus, the number of questionnaires that were analyzed was 72 .

\section{The study tool :-}

A questionnaire was developed using the literature reviews in order to collect the data that measure the variables of the study and the respondents answered. This questionnaire was divided into three parts as follows:

Part I : It consists of a set of items concerning the personal and professional data of the sample of the study population.

Part II : The independent variable, "Health Information Systems," has been tackled. This part has been divided into the following dimensions:

The first dimension : The hardware requirements were measured in items (1-4).

The second dimension : The software requirements were measured in items (5-8).

The third dimension: The human requirements were measured in items (9-12).

The fourth dimension : The organizational requirements were measured in items (13-16).

Part III : The dependent variable "The performance of human resources" with its dimensions (motivation, ability and perception) was measured in items (17-24).

The Likert scale was used, and the weight of those items was determined as shown in the following table:

Table (1) : Scale of approval according to Likert scale

\begin{tabular}{|c|c|c|c|c||}
\hline Strongly & Disagree & Neutral & Agree & Strongly agree \\
\hline 1 & 2 & 3 & 4 & 5 \\
\hline
\end{tabular}

The weights of the mean averages and the level of importance were also measured by the following equation :-

$$
\text { Application Level }=\frac{\text { Upper Score - Lower Score }}{3}=\frac{5-1}{3}=1.33
$$

Therefore, if the value of the mean average of the items is (1.00 - 2.33), it indicates that the level of perceptions of the population of the study sample is low. If the value of the mean of the items is $(2.34-3.66)$, this means that the perceptions of the population of the study sample is 
average, whereas if the value of the mean average of the items is (3.67 - 5.00), it indicates that the level of perceptions of the populations of the study sample is high.

\section{Reliability and stability of study tool : -}

The truthfulness test was conducted for the study tool. To verify the validity of the tool, a verifiable veracity of the questionnaire was done by presenting it to 8 referees in the field of MIS, IT and business administration. The referees were asked to assess the relevance of the questions and the degree of appropriateness of each item for each of the areas, assess the appropriateness and comprehensiveness of the items to the dimensions, and to make any appropriate amendments, and in accordance with the views of the referees, a number of items were deleted and some of them were reworded into a 24 items. In addition, the questionnaire was distributed to a sample of staff of 20 employees so as to know the clarity and easiness of terms used and the extent of their understanding of the concepts contained in this questionnaire, and then make the necessary adjustments.

\section{Stability of the study tool :-}

The stability coefficient value was calculated according to the Cronbach-Alpha coefficient in order to ensure the internal consistency of all items of the questionnaire. The results indicate that the stability coefficient for all dimensions was $87.4 \%$, indicating that the study tool is stable and valid for statistical analysis and scientific research (Sakaran, 2010).

Table (2) : shows the consistency coefficient of the internal consistency of the dimensions of the questionnaire (Cronbach - Alpha).

\begin{tabular}{|c|l|c|c|}
\hline \multirow{2}{*}{ Variables } & \multicolumn{1}{|c|}{ Dimensions } & $\begin{array}{c}\text { No. of } \\
\text { items }\end{array}$ & $\begin{array}{c}\text { consistency coefficient } \\
(\boldsymbol{\alpha}) \text { Cronbach - Alpha }\end{array}$ \\
\hline \hline \multirow{2}{*}{$\begin{array}{c}\text { Dimensions of } \\
\text { independent } \\
\text { variable }\end{array}$} & Hardware requirements & 4 & $69.4 \%$ \\
\cline { 2 - 4 } & Software requirements & 4 & $77.6 \%$ \\
\cline { 2 - 4 } & $\begin{array}{l}\text { Human resources } \\
\text { requirements }\end{array}$ & 4 & $76.6 \%$ \\
\cline { 2 - 4 } & Organizational requirements & 4 & $86.6 \%$ \\
\hline $\begin{array}{c}\text { dependent } \\
\text { variable }\end{array}$ & $\begin{array}{l}\text { Human resources } \\
\text { performance }\end{array}$ & 8 & $89.4 \%$ \\
\hline Total & Hardware requirements & $\mathbf{2 4}$ & $\mathbf{8 7 . 4 \%}$ \\
\hline
\end{tabular}

\section{Statistical processing :-}

In order to answer the study questions and to test their hypotheses, the study relied on the statistical package (SPSS) in the analysis, using the following statistical methods, namely the descriptive statistics and the Alpha Cronbach $(\alpha)$. The aim of this equation is to ensure the stability of the questionnaire sections and the Multi Regression Analysis to test the validity of the study model, and to test the impact of each independent variable and its dimensions on the dependent variable, and the $\mathrm{F}$ test to verify the significance of the relationship between the study variables and the One Way ANOVA test to test the hypotheses to ensure the existence of statistically significant differences due to personal and professional variables.

\section{Procedural Definitions and Study Variables :-}

\section{1) Independent variable : -}

* Health Information Systems : A set of hardware, hardware, networks and software that processes data and transforms it into useful information for the organization.

* Hardware requirements : Devices and networks used in the IS, including I / 0 and CPU. 
* Software requirements : The software package that is used to run and manage system devices in addition to the software application used in the performance of work.

* Human requirements : The body responsible for maintaining the system and networks to address the problems faced by users while using the computerized information system.

* Organizational requirements : The support of senior management to use the information system and the ability of the system to provide information to users without regulatory restrictions.

\section{2) The Dependent variable : -}

* The performance of human resources : performing the tasks and duties required by the job they occupy, an activity or effort made by the individual, whether mentally or intellectually to complete the tasks assigned to him where this behavior makes a change that would achieve the objectives planned by the organization (Jabr, 2010), including: -

* Motivation : The individual's desire to exert maximum efforts to achieve the organizational goals in order to increase his ability to enable his needs and thus are internal engines of behavior (Qaryuti, 2003).

* Capacity : The mental and hardware preparations and abilities to perform multiple tasks (Sultan, 2004).

* Perception : The process by which the individual organizes and interprets his sensory impressions, in order to add meaning to the environment in which he exists (Hassan, 2000).

\section{LITERATURE REVIEW}

\section{First : The theoretical framework.}

The recent rapid development of medical and health services has called for increased demand for appropriate health information for medical and administrative decisions. Health managers and policy makers need appropriate and accurate information to measure the effectiveness of programs and follow their progress to achieve the desired goals. Therefore, investing in health information systems will be justified, since it helps improve performance and decision-making in the detection and control of health problems (WHO, 2009).

\section{Concept of computerized health information systems : -}

The World Health Organization (WHO) has defined the computerized health information system as "the science of acquiring, preserving, retrieving and applying biomedical knowledge and information to improve the patient's care, education and electronic medical search (Shurbagi, 2007). The Regional Office for the Eastern Mediterranean defines it as "a comprehensive term that uses computing methodologies, technologies, networks and communications to support health-related areas such as medicine, nursing and management, in order to maintain, process, retrieve and share patient-related management and clinical information through the electronic health record" (Dweik, 2010).

\section{The importance of health information systems :-}

Health information systems aim to access, manage and use information to improve the performance and the better management in order to provide necessary support to health care services. The provision of health services to the population is a highly information-based goal, which hospitals seek to get health care information for each patient, the consequent results, and the performance in the delivery of services and their integration with information. These systems are a single entity, starting with patient data, "clinical data", and collected data "performance, usage, etc." directing it towards knowledge-based data, "Planning and Health Decision Support" and the collected data, "Medical or health policy-making" (Schoen, 2012). 


\section{Computerized Health Information Systems at King Faisal Specialist Hospital in Taif Governorate :-}

Health information systems, like any other system consisting of input, processing and output units, are composed of integrated subsystems that interact with one another in an open environment that directly and indirectly contributes to health care. These systems include:

First : Patient Registration and Master Index: - A system through which the patient data is recorded in full, such as personal data, date of birth, job, nationality, address, nearest relatives, infectious diseases, medical insurance and the attending doctor of the patient.

Second : Administration Add Discharge System: - A system in which the Admission Inpatient are recorded.

Third : Laboratory Information System: - A system for the management of the hospital's medical laboratory through which the registration of forms, reception of samples, and the entry, verification and printing of results of tests.

Fourth : Emergency System: - a system through which the patient's emergency registration, registration of emergency services provided to the patient and registration of judicial cases are recorded.

Fifth : Outpatient Scheduling System: a system that records the patient's visit to the outpatient clinic, recording the initial tests, and diagnosing the patient's condition using ICD10.

Sixth : Pharmacy Information System: a system used to enter the data of medicines, alternative medicines, prescriptions, and the registration of drug exchange movements in the pharmacy and the automatic medication for the admitted patients.

Seventh : Radiology Information System: a system that records applications, enters and verifies results, writes and prints medical reports, such as CT scans, MR, and UltraSound TV, and links these reports to the patient's record.

Eighth : Inpatient Information System: a system that records all performed medical procedures, inpatient and outpatient cases for the admitted patients, attendant data, and the transfer of patients from one department to another within the hospital.

Ninth : Dietary Information System: - a system to enter and determine the appropriate meals for the patient, and the calculation of the quantities of food required for each day and print detailed reports and number of the meals required per day, and indicate the room number and bed for each patient.

Tenth : Accounting Information System: - a system linked with the subsystems of the hospital information system that produces a detailed statement of the patient's total, on demand, and gives details of all actions and procedures provided to the patient and calculate the financial value to be paid by the patient.

Eleven : E-Mail System: a system through which messages, circulars, invitations to meetings and sending files of various types to users are recorded. Through e-mail, the hospital is administratively linked from top to bottom and horizontally to centralize monitoring and decentralization of work so that effective management can be applied.

\section{The most important factors that helped hospitals use computerized health information systems (Annajjar, 2007):}

1. Low cost of computers and provision of trained manpower in addition to the accuracy and speed of information availability.

2. Easy programming of many health activities using the computer.

3. Easy storage of information media on the computer.

\section{Objectives of computerized health information systems:}

There are a set of goals that health information systems seek to achieve (WHO, 2000), including: 
1. To detect and respond quickly to health problems and the spread of epidemics.

2. Evaluate the effectiveness of the task and health performance and services provided in the hospital.

3. Ensure the delivery of resources and health services to various departments and outpatient clinics.

4. Integrity by linking health systems and subsystems together.

5. Dissemination of health information and health education through training and development programs.

\section{Comprehensive health (IS) include the following components (Annajjar, 2007) :-}

1. Basic criteria for exploiting hospital resources and determining final results based on the operation of accounting data.

2. Providing an adequate supply of information on demand for health services geographically.

3. Entering, storing and retrieving information while providing this data for specialized activities and routine health services.

4. Providing data on the performance of the hospital staff which helps in providing information used in recruitment and planning.

\section{THE CONCEPT OF HUMAN RESOURCES PERFORMANCE (HR)}

The concept of human resource performance is one of the concepts that have received a great deal of attention and research in management studies in general and human resources studies in particular because of the importance of the concept at the level of the individual and the organization, and the interaction of influences and their diversity that affect performance. It also has defined the performance of human resources as "the best use of the hardware and human resources available to achieve the objectives of the organization and maintain its competitive advantage" (Robbins, 2008). Performance is also defined as: - "the ability of the individual to achieve the objectives of the organization through the optimal use of available resources in an efficient and effective manner" (Daft, 2011).

\section{The relationship of computerized health information systems to the performance of human resources :-}

Information technology has become a catalyst for organizations looking for competition and excellence in their production, outputs, efficiency and effectiveness in their performance. Therefore, the organizations have accelerated to prepare the ground for their implementation and then use them to create unprecedented opportunities in several areas such as improving human resources performance, improving the administrative decisions, simplifying and facilitating procedures and optimal utilization of the organization's workforce, through the implementation of a number of procedures and changes in the structure, processes and management of the organization and training users on how to use to ensure their work correctly and to achieve performance standards which the organization attempts to achieve. Therefore, the relationship between the use of computerized health information systems and the performance of human resources is strong due to the following reasons (Arabi, 2012):

1. Improving the performance of human resources by overcoming many of the routine work and the consequent completion of the work quickly, efficiently, accurately and at low costs.

2. Reducing the routine administrative burdens on managers, allowing them to take advantage of this time in strategic planning and policy formulation of the organization which contributes to increasing the efficiency and effectiveness of senior management. 
The role of computerized health information systems in the process of improving the performance of human resources and making health decisions :-

Computerized health information systems play an important role in increasing the efficiency and effectiveness of human resources performance and decision-making. The World Health Organization (WHO) considers that the inefficiency and inefficacy of decisions taken in health institutions is the result of the lack of information and the atrophy of the channels and tools responsible for their collection, transporting, indexing and processing that make them suitable for use in various stages of the proper medical decision making, whether it is a prescription for a patient with an illness or a health strategy such as the control of epidemic diseases such as swine flu, schistosomiasis, or hepatitis, therefore; health information systems are able to get rid of the lack of effective and efficient administrative and wrong medical decisions (WHO, 2009). Health information systems improve performance and decision-making as follows (Dweik, 2010):

1. It is considered the cornerstone of knowing the prevalence and causes of disease and its causes accurately and quickly.

2. The decision maker can immediately identify the status of the stock of medicines and medical supplies in the hospital and prepare a list of medical purchases.

3. Monitor the level of performance in all hospital facilities to avoid the disadvantages and errors common in the hospital accurately.

4. Monitor financial performance in real terms and calculate any over-treatment costs.

5. To draw accurate statistics on the results of surgical operations and their number and mortality rate in different specialties.

\section{PREVIOUS STUDIES}

The previous studies aimed at addressing a set of studies related to the subject of health information systems in relation to the performance of human resources, directly or indirectly. They were reviewed in chronological order as follows:

(Al-Gharabawi, 2014) Computerized Health Information Systems and Their Relationship to Job Performance - A Field Study on UNRWA Centers for Health Care in Gaza Strip. The study used the descriptive analytical method. The study included (9) centers out of (21) health centers. The questionnaire was used as a tool for study. 216 questionnaires were retrieved out of 270 questionnaire distributed at a recovery rate of $80 \%$. The study concluded a number of results :-

1. There is a high degree of approval by the members of the study population regarding the possibilities available for the use of computerized health information systems and their applications and the level of performance of human resources.

2. There is a positive relationship between computerized health information systems and profession performance in the centers of the agency.

(Al-Awadi, 2013) The role of health information systems in developing the capacities of employees in public hospitals in Gaza Strip. The study aims at revealing the role of health information systems in developing the abilities of employees in government hospitals in Gaza Strip from the point of view of the administrative staff working in hospitals in Gaza Strip. The study population consists of (149) employees while the questionnaire sample reached (62). The sample of the field study has been chosen in a random stratified manner, and a special questionnaire has been developed to collect the data in order to identify the role of health information systems in developing the abilities of the hospital staff from the point of view of the employees themselves. The study concludes a No of results, the most important of which are: 
1. The highest level of availability of health information systems components in government hospitals was the axis of the software components with a relative weight of (76.8\%), followed by human components with a high relative weight of $(74.11 \%)$, followed by the availability of organizational components with a high relative weight of $72.97 \%$, whereas the hardware components were lowest level of availability of the components of health information systems in public hospitals with a weight of (70.31\%), and the total score for all components of the system components together with a high relative weight of $(73.54 \%)$.

2. There is a statistically significant relationship between health information systems and the development of workers' abilities from the point of view of employees in government hospitals in the southern Gaza Strip.

The study recommended emphasizing the role of health information systems in government hospitals in developing the abilities of employees and giving employees training courses in both administrative and technological aspects of these systems.

(Alarabi, 2012) study entitled the impact of the use of information technology on job performance in local government agencies. The study aimed to identify the impact of the use of information technology on the performance of local government agencies. To achieve this goal, a questionnaire was designed for the purpose of collecting data and information. The study concludes the following results:

1. There is a statistically significant relationship between the use of information technology and the performance of human resources.

2. There is a statistically significant relationship between the use of information technology, size, quality and efficiency of performance and simplification of work.

(Dweik, 2010) The implications of the use of computerized health information systems on the decision-making process of the Gaza State Hospital. The aim of the study was to determine the implications of using these systems, to identify the differences between the effects of these systems on the administrative decisions compared to the medical decisions, and also to analyze the actual reality of the use of computerized health information systems in different departments and the effects of using these systems on the administrative work fields. The study concluded a number of results, the most important of which are:

1. The number of members of the administrative and medical sample who use these systems in their work was (121) out of (128) individuals.

2. The health information system currently used in Gaza Hospital has a significant impact on medical and administrative aspects of medical and administrative decisions.

(Schoen and others, 2012) The Extent of the use of Primary Care Physicians to Health Information Systems and their Impact on Performance. This study aimed at identifying the extent to which primary health care physicians use health information systems and their impact on performance. The researchers conducted a survey of primary health care physicians in 10 countries (Australia, Canada, France, Germany, Netherlands, New Zealand, Norway, Switzerland, United Kingdom and the United States). The study concluded a number of results, the most important of which are:

1. There is a good proportion in the ten countries indicate improvement in the performance of the physician.

2. Majority of the American physicians were of the opinion that there should be a fundamental change in the current primary care system. 
(Marques and others, 2011) Medical Records System Adoption in European Hospitals. The aim of this study was to investigate the analysis of the use of the computerized medical records system (MRS) in European hospitals. Data were collected from (448) hospitals of the European Union countries using the e-Business @ tch 2006 model for a comprehensive survey of decision-makers as well as official statistics published by EU offices. The researchers developed a new model to evaluate the acceptability of the study sample for the use of computerized medical record systems. A new factor, HOT-Fit, was added to study the relationship between technological, human and organizational factors. The computerized medical records system model was used. The study concluded that there was a statistically significant relationship between the adoption of electronic health systems due to the technological variables and the level of education and the country's economic capability.

(Alyaseen and others, 2010) Post-Implementation Evaluation of Health Information Systems in Developing Countries. The aim of this study was to investigate the reality of using two models for evaluating health information systems: assessing operational pre-use and assessing the actual operational use of private Jordanian hospitals to understand the requirements and benefits of the assessment process and to collect information on the actual use of the evaluation process by these hospitals. To do this, the researchers worked on a questionnaire containing a number of questions, such as the nature of the use of the preoperational use assessment model, the actual operational use assessment model, the criteria used in both models, and the benefits of using both models, after being distributed among the related staff. The study found that most decision makers do not care for using the actual operational use assessment model in the process of evaluating their computerized health information systems.

Description of the study sample characteristics :-

Table (3) : shows the frequency and percentage of the sample of the study population

\begin{tabular}{|c|c|c|c|}
\hline Variable & Category & frequency & percentage $\%$ \\
\hline \multirow{5}{*}{ Age } & Less Than 30 Year & 9 & $12.5 \%$ \\
\hline & $31-40$ Year & 31 & $43.05 \%$ \\
\hline & $41-50$ Year & 18 & $25 \%$ \\
\hline & More than 51 Year & 14 & $19.45 \%$ \\
\hline & Total & 72 & $100 \%$ \\
\hline \multirow{5}{*}{ Qualification } & $\begin{array}{c}\text { Less Than General Secondary } \\
\text { School }\end{array}$ & 3 & $4.17 \%$ \\
\hline & bachelor & 42 & $58.33 \%$ \\
\hline & Master & 19 & $26.38 \%$ \\
\hline & $\mathrm{PhD}$ & 8 & $11.11 \%$ \\
\hline & Total & 72 & $100 \%$ \\
\hline \multirow{5}{*}{ Experience } & Less Than 5 Years & 7 & $9.72 \%$ \\
\hline & $6-10$ Years & 12 & $16.66 \%$ \\
\hline & $11-15$ Year & 32 & $44.44 \%$ \\
\hline & More than 16 Year & 21 & $29.18 \%$ \\
\hline & Total & 72 & $100 \%$ \\
\hline
\end{tabular}

\section{Age Variable : -}

The percentage of the 30 years of age category was the lowest $12.5 \%$ of all respondents. The years of age category 31- 40 years was $43.05 \%$, followed by the age category 41-50 years of 25 $\%$. The age category of 51 years and above showed a percentage of $19.45 \%$. This indicates that 
the majority of employees in leading positions are young people, where their efficiency and activity are greater than the rest of the older age categories.

\section{Qualification Variable : -}

The bachelor's degree category was the highest with $58.33 \%$ of the total number of respondents, while the lowest percentage (secondary or lower secondary qualification) was $4.17 \%$ of respondents. The results indicate that the majority of department heads and managers in the hospital are university graduates and qualified scientifically to understand health information systems with high efficiency.

\section{Professional experience Variable : -}

Most of the respondents were 11 to 15 years of age, with $44.44 \%$ of all respondents, while the lowest percentage was 5 years category with $9.72 \%$ of all respondents. This means that there is a professional stability in the hospital, particularly the heads of departments and directors in the hospital.

Part II : A group of items dealing with (the impact of health information systems) on the performance of human resources in King Faisal Hospital in Taif from the point of view of the sample members.

The results of descriptive statistical analysis, the relative importance of all study variables, and the constituent items of each variable on the Five Likert scale are presented below.

First : The independent variable "health information systems" (hardware requirements, software requirements, human requirements, and organizational requirements). This variable is divided into a number of dimensions:

Tables (5-8) show the mean, standard deviation, and significance level of the sample of the study population at King Faisal Specialist Hospital in Taif Governorate regarding the use of health information systems in their four dimensions.

First dimension: The Hardware requirements were measured in the following paragraphs.

1. Available computers are suitable for the work required and the needs of work in the hospital.

2. The speed of the devices commensurate with the size of work required to be performed in the hospital.

3. The communication network used in the hospital is characterized by rapid communication.

4. When the communication network is malfunctioning, it is processed quickly.

Table (4) : The mean, the standard deviation and the relative importance of the estimation of the sample members

\begin{tabular}{|c|c|c|c|c|}
\hline Item No. & Mean & St. Dev. & Sig. & Rank \\
\hline \hline 1 & 4.43 & 0.747 & 0.000 & 1 \\
\hline 2 & 4.11 & 0.723 & 0.000 & 3 \\
\hline 3 & 4.32 & 0.709 & 0.000 & 4 \\
\hline 4 & 4.40 & 0.685 & 0.000 & 2 \\
\hline In General & $\mathbf{4 . 3 2}$ & $\mathbf{0 . 4 6 5}$ & & \\
\hline
\end{tabular}

The results of the analysis in the previous table indicate that the dimension of the independent variable "hardware requirements", achieved a high mean of 4.32 was achieved with a standard deviation of 0.465 . Paragraph 1 achieved a higher mean of 4.43 and a standard deviation of 
0.747. As the available computers are suitable for the work required and the needs of work in the hospital and have sufficient capacity to achieve the desired goal of the health information system. Which is statistically significant at the level of $\alpha \leq 0.05$, indicating to the significance of the estimate based on the mean.

second dimension : The software requirements were measured in the following paragraphs.

5. The software used commensurate with the requirements and need of hospital work and are updated.

6. The software is compatible with the devices used and covers all activities performed by the hospital.

7. The software and network used in hospital work are compatible.

8. All instructions are available to run the software hospital needs in performing work are available.

Table (5) : The mean, the standard deviation and the relative importance of the estimation of the sample members

\begin{tabular}{|c|c|c|c|c||}
\hline Item No. & Mean & St. Dev. & Sig. & Rank \\
\hline \hline 5 & 4.43 & 0.709 & 0.000 & 2 \\
\hline 6 & 4.76 & 0.569 & 0.000 & 1 \\
\hline 7 & 4.28 & 0.755 & 0.000 & 4 \\
\hline 8 & 4.32 & 0.646 & 0.000 & 3 \\
\hline In General & $\mathbf{4 . 4 5}$ & $\mathbf{0 . 4 6 8}$ & & \\
\hline
\end{tabular}

The results of the analysis in the previous table indicate that the dimension of the independent variable "software requirements" achieved a high mean of 4.45 and a standard deviation of 0.468. Item 6 achieved a higher mean of 4.76 and a standard deviation of 0.569 , where the software is compatible with the devices used and covers all the activities in the hospital. This is statistically significant at the level of $\alpha \leq 0.05$, indicating the significance of the estimation based on the mean.

\section{The Third dimension : Human requirements were measured in the following paragraphs.}

9. The staff of the specialized technical department in the hospital has a high degree of efficiency.

10. The technical department concerned with the system addresses the problems facing the hospital staff in using the system or network.

11. Contact with the health information system Department is made directly.

12. The technical specialist in the health information system shall respond promptly to any query requested regarding the work.

Table (6) : The mean, the standard deviation and the relative importance of the estimation of the sample members

\begin{tabular}{|c|c|c|c|c||}
\hline Item No. & Mean & St. Dev. & Sig. & Rank \\
\hline \hline 9 & 4.18 & 0.811 & 0.000 & 2 \\
\hline 10 & 4.00 & 0.712 & 0.000 & 3 \\
\hline 11 & 3.97 & 0.731 & 0.000 & 4 \\
\hline 12 & 4.24 & 0.741 & 0.000 & 1 \\
\hline In General & $\mathbf{4 . 0 9}$ & $\mathbf{0 . 4 9 4}$ & & \\
\hline
\end{tabular}

The results of the analysis shown in the above table indicate that the dimension of the independent variable "human requirements," achieved a high mean of 4.09 with a standard 
deviation of 0.494 . Item 12 achieved the highest mean of 4.24 and a standard deviation of 0.741. where the technical specialist in the health information system should respond promptly to any query requested regarding the work. This is statistically significant at the level of $\alpha \leq 0.05$, indicating to the significance of the estimation based on the mean.

\section{Fourth dimension : Organizational requirements is measured by the following items.}

13. Senior management is concerned with developing the hospital's health information system and providing training programs related to the use of the system.

14. The senior management follows up the functioning of the health information system in the hospital.

15. Senior management is concerned with the suggestions of the staff about the health information system used in the hospital.

16. Providing supervision by the senior management for all operations carried out on the health information system used.

Table (7) : The mean, the standard deviation and the relative importance of the estimation of the sample members

\begin{tabular}{|c|c|c|c|c||}
\hline Item No. & Mean & St. Dev. & Sig. & Rank \\
\hline \hline 13 & 4.46 & 0.691 & 0.000 & 1 \\
\hline 14 & 4.33 & 0.751 & 0.000 & 2 \\
\hline 15 & 4.29 & 0.680 & 0.000 & 3 \\
\hline 16 & 3.82 & 0.811 & 0.000 & 4 \\
\hline In General & $\mathbf{4 . 2 3}$ & $\mathbf{0 . 4 4 4}$ & & \\
\hline
\end{tabular}

The results of the analysis in the above table indicate that the dimension of the independent variable "organizational requirements" achieved a high mean of 4.23 and a standard deviation of 0.444 . Items 13 achieved the highest mean of 4.46 and a standard deviation of 0.691 . where the senior management is concerned with developing the hospital health information system and providing training programs on the use of the health information system. This is statistically significant at the level of $\alpha \leq 0.05$ indicating the significance of the estimation based on the mean.

\section{Part II : Performance of human resources in King Abdul-Aziz Specialist Hospital.}

17.I am highly regarded by my seniors when I achieve a high level of performance.

18. Hospital staff is subject to actual performance benchmarks.

19. The hospital grants me appropriate incentives.

20. The type of job I occupy fits my own abilities.

21. The hospital is concerned with developing the abilities of the staff.

22. My ability to accomplish is good because I do my best.

23. I realize that I am totally responsible for the work I do.

24. I develop my performance and skills constantly. 
Table (8) : The average and the standard deviation for the estimation of the sample members in terms of motivation, ability and perception

\begin{tabular}{|c|c|c|c|c|}
\hline Item No. & Mean & St. Dev. & Sig. & Rank \\
\hline \hline 17 & 4.29 & 0.740 & 0.000 & 2 \\
\hline 18 & 3.85 & 0.781 & 0.000 & 7 \\
\hline 19 & 4.07 & 0.775 & 0.000 & 6 \\
\hline 20 & 4.18 & 0.811 & & 3 \\
\hline 21 & 4.36 & 0.678 & & 1 \\
\hline 22 & 4.13 & 0.691 & & 5 \\
\hline 23 & 3.26 & 0.531 & & 8 \\
\hline 24 & 4.17 & 0.411 & 0.000 & 4 \\
\hline In General & $\mathbf{4 . 0 4}$ & $\mathbf{0 . 6 7 8}$ & & \\
\hline \hline
\end{tabular}

The results of the analysis in the above table indicate that the variable "human resources performance" achieved a high mean of 4.044 and a standard deviation of 0.678 . Item 21 achieved the highest mean of 4.36 and a standard deviation of 0.678 where the hospital is concerned with developing the abilities of the staff. which is statistically significant at the level of $\alpha \leq 0.05$ indicating the significance of the estimation based on the mean.

\section{The First Main Hypothesis : -}

\section{TESTING HYPOTHESES}

There was no statistically significant effect at the level of $\alpha \leq 0.05$ for the use of health information systems (hardware, software, human and organizational requirements) on the performance of human resources at King Faisal Specialist Hospital in Taif.

* To test this hypothesis, Multi Regression analysis was used to verify the impact of health information systems combined (hardware, software, human and organizational requirements) on human resource performance as shown in the following table :-

Table (9) : Multiple Regression Analysis Results of the Impact of Health Information Systems on Human Resource Performance

\begin{tabular}{|c|c|c|c|c|c|c|c|c|c|}
\hline $\mathrm{R}$ & $\mathrm{R}^{2}$ & $\mathrm{~F}$ & $\mathrm{df}$ & & $\operatorname{Sig} .^{*}$ & $\beta$ & & $\mathrm{T}$ & $\operatorname{Sig} .^{*}$ \\
\hline \multirow{4}{*}{$0.585^{\mathrm{a}}$} & \multirow{4}{*}{0.343} & \multirow{4}{*}{8.734} & Regression & 4 & \multirow{4}{*}{$0.000^{\mathrm{b}}$} & Hardware Req. & 0.461 & 4.301 & \multirow{4}{*}{$0.000^{\mathrm{b}}$} \\
\hline & & & Residual & 67 & & Software Req. & 0.111 & 3.052 & \\
\hline & & & \multirow{2}{*}{ Total } & \multirow{2}{*}{71} & & Human Req. & 0.206 & 2.153 & \\
\hline & & & & & & Organizational & 0.327 & 3.841 & \\
\hline
\end{tabular}

The results of statistical analysis showed a statistically significant effect of health information systems on the performance of human resources in King Faisal Specialist Hospital.

The simple correlation coefficient $\mathrm{R}=0.585$ at the level of $\alpha \leq 0.05$ and the coefficient of determination $\mathrm{R}^{2}=0.343$ which means that $34.3 \%$ of the changes in human resources performance are due to changes in the dimensions of health information systems. The value of the degree of the impact of hardware requirements was $\beta=0.461$, the value of the degree of the impact of the software requirements was $\beta=0.111$, the value of the degree of the impact of human requirements was $\beta=0.206$ and the value of the degree of the impact of the organizational requirements was $\beta=0.327$. This means that the increase at one level of attention to health information systems in its dimensions leads to an increase in the 
performance of human resources by $46.1 \%$ for the hardware requirements, $11.1 \%$ for software requirements, $20.6 \%$ for human requirements and $32.7 \%$ for organizational requirements. The significance of this impact confirms the calculated $F$ value of 8.734 which is a function at $\alpha \leq 0.05$ and this confirms that the first major hypothesis is incorrect.

\section{The decision :-}

To reject the null hypothesis in its current form and to accept the alternative hypothesis which states that there is a statistically significant effect at the level of significance $\alpha \leq 0.05$ for the use of health information systems (hardware, software, human and organizational requirements) on the performance of human resources at King Faisal Specialist Hospital in Taif.

In order to investigate the impact of each dimension of the health information systems on the performance of human resources at King Faisal Specialist Hospital in Taif Governorate, the main hypothesis was divided into four sub-hypotheses.

To test the sub-hypotheses of this hypothesis, simple regression was used as follows: The First-sub hypothesis :-

There was no statistically significant effect at the level of $\alpha \leq 0.05$ for the hardware requirements of health information systems on the performance of human resources at King Faisal Specialist Hospital in Taif.

Table (10) : Results of the simple regression test for the impact of hardware requirements on the performance of human resources

\begin{tabular}{|c|c|c|c|c|c|c|c|c|c|}
\hline $\mathrm{R}$ & $\mathrm{R}^{2}$ & $\mathrm{~F}$ & \multicolumn{2}{|l|}{$\mathrm{df}$} & Sig .* & $\beta$ & $\mathrm{T}$ & Sig.* & Decision \\
\hline \multirow{3}{*}{$0.537^{a}$} & \multirow{3}{*}{0.288} & \multirow{3}{*}{28.369} & Regression & 1 & \multirow{3}{*}{$0.000^{\mathrm{b}}$} & \multirow{3}{*}{$0.537^{a}$} & \multirow{3}{*}{5.326} & \multirow{3}{*}{$0.000^{\mathrm{b}}$} & \multirow{3}{*}{$\begin{array}{c}\text { Reject } \\
\text { Hypothesi } \\
\mathrm{s}\end{array}$} \\
\hline & & & Residual & 70 & & & & & \\
\hline & & & Total & 71 & & & & & \\
\hline
\end{tabular}

The results of the statistical analysis showed a statistically significant impact on the hardware requirements on the performance of human resources in King Faisal Specialist Hospital.

The simple correlation coefficient was $R=0.537$ at the level of $\alpha \leq 0.05$ and $R^{2}=0.288$, i.e. the value of $28.8 \%$ of the changes in human resources performance is due to the change in the level of attention to hardware requirements. This means that the increase of one degree in the level of attention to hardware requirements leads to an increase in the improvement of human resources performance by $53.7 \%$. The significance of this impact confirms the calculated $\mathrm{F}$ value of 28.369 which is significant at $\alpha \leq 0.05$ and the calculated $T$ value of 5.326 , which is significant at $\alpha \leq 0.05$. This confirms that the first sub-hypothesis is incorrect.

\section{The decision :-}

Rejecting the current nihilistic hypothesis and accepting the alternative hypothesis.

\section{The Second-sub hypothesis:-}

There was no statistically significant effect at the level of $\alpha \leq 0.05$ for the software requirements of health information systems on the performance of human resources in King Faisal Specialist Hospital in Taif. 
Table (11) : Simple regression results of the impact of software requirements on the performance of human resources

\begin{tabular}{|c|c|c|c|c|c|c|c|c|c|}
\hline $\mathrm{R}$ & $\mathrm{R}^{2}$ & $\mathrm{~F}$ & \multicolumn{2}{|l|}{$\mathrm{df}$} & Sig .* & $\beta$ & $\overline{\mathrm{T}}$ & Sig .* & Decision \\
\hline \multirow{3}{*}{$0.275^{\mathrm{a}}$} & \multirow{3}{*}{0.076} & \multirow{3}{*}{5.717} & Regressio & 1 & \multirow{3}{*}{$0.000^{\mathrm{b}}$} & \multirow{3}{*}{0.275} & \multirow{3}{*}{2.391} & \multirow{3}{*}{$0.019 \mathrm{~b}$} & \multirow{3}{*}{$\begin{array}{c}\text { Reject } \\
\text { Hypothesis }\end{array}$} \\
\hline & & & Residual & 70 & & & & & \\
\hline & & & Total & 71 & & & & & \\
\hline
\end{tabular}

The results of the statistical analysis showed a statistically significant impact of the requirements of the software on the performance of human resources in King Faisal Specialist Hospital. The simple correlation coefficient was $\mathrm{R}=0.257$ at the level of $\alpha \leq 0.05$ and $\mathrm{R}^{2}=$ 0.076 , i.e. $7.6 \%$ of the changes in human resources performance due to the change in the level of attention to the requirements of the software, and the degree of impact of the hardware requirements $\beta=0.275$. This means that the increase of one degree in the level of attention to the requirements of the software leads to an increase in the performance of human resources by $27.5 \%$ and confirms the significance of this effect value of calculated $\mathrm{F}$, which amounted to 5.717, which is significant at the level of $\alpha \leq 0.05$ This confirms that the second hypothesis is incorrect.

\section{The decision :-}

Rejecting the null hypothesis and accepting the alternative hypothesis.

\section{The Third-sub hypothesis :-}

There was no statistically significant effect at the level of $\alpha \leq 0.05$ for the human requirements of health information systems on the performance of human resources at King Faisal Specialist Hospital in Taif.

Table (12) : Results of the simple regression test for the impact of human requirements on the performance of human resources

\begin{tabular}{|c|c|c|c|c|c|c|c|c|c|}
\hline $\mathrm{R}$ & $\mathrm{R}^{2}$ & $\mathrm{~F}$ & \multicolumn{2}{|l|}{$\mathrm{df}$} & Sig.* & $\beta$ & $\mathrm{T}$ & Sig .* & Decision \\
\hline \multirow{3}{*}{$0.347^{a}$} & \multirow{3}{*}{0.121} & \multirow{3}{*}{9.599} & Regressio & 1 & \multirow{3}{*}{$0.009^{b}$} & \multirow{3}{*}{0.347} & \multirow{3}{*}{3.098} & \multirow{3}{*}{$0.003^{\mathrm{b}}$} & \multirow{3}{*}{$\begin{array}{c}\text { Reject } \\
\text { Hypothesis }\end{array}$} \\
\hline & & & \begin{tabular}{|l} 
Residual \\
\end{tabular} & 70 & & & & & \\
\hline & & & Total & 71 & & & & & \\
\hline
\end{tabular}

The results of the statistical analysis showed a statistically significant impact of human requirements on the performance of human resources in King Faisal Specialist Hospital.

The simple correlation coefficient was $\mathrm{R}=0.347$ at the level of $\alpha \leq 0.05$ and $\mathrm{R}^{2}=0.121$, i.e. 12.1 $\%$ of the changes in human resource performance resulted from the change in the level of attention to human requirements. The value of the degree of the impact of hardware requirements was $\beta=0.347$ This means that the increase of one degree in the level of attention to human requirements leads to an increase in the improvement of the performance of human resources by $34.7 \%$, and confirms the significance of this impact calculated $\mathrm{F}$ value which amounted to 9.599, which is significant at the level of $\alpha \leq 0.05$ and the value of calculated $\mathrm{T}$ at 3.098, which reached a function at the level $\alpha \leq 0.05$ and confirms that the third sub-hypothesis is incorrect. 


\section{The decision :-}

Rejecting the null hypothesis and accepting the alternative hypothesis.

\section{The Fourth-sub hypothesis :-}

There was no statistically significant impact at the level of $\alpha \leq 0.05$ for the organizational requirements of health information systems on the performance of human resources at King Faisal Specialist Hospital in Taif Governorate.

Table (13) : Results of simple regression test for the impact of organizational requirements on human resources performance

\begin{tabular}{|c|c|c|c|c|c|c|c|c|c|}
\hline $\mathrm{R}$ & $\mathrm{R}^{2}$ & $\mathrm{~F}$ & \multicolumn{2}{|l|}{$\mathrm{df}$} & Sig.* & $\beta$ & $\mathrm{T}$ & Sig .* & Decision \\
\hline \multirow{3}{*}{$0.262^{\mathrm{a}}$} & \multirow{3}{*}{0.069} & \multirow{3}{*}{5.161} & Regressio & 1 & \multirow{3}{*}{$0.026^{\mathrm{b}}$} & \multirow{3}{*}{0.262} & \multirow{3}{*}{2.272} & \multirow{3}{*}{$0.026^{\mathrm{b}}$} & \multirow{3}{*}{$\begin{array}{c}\text { Reject } \\
\text { Hypothesis }\end{array}$} \\
\hline & & & Residual & 70 & & & & & \\
\hline & & & Total & 71 & & & & & \\
\hline
\end{tabular}

The results of the statistical analysis showed a statistically significant impact of the organizational requirements on the performance of human resources in King Faisal Specialist Hospital. The simple correlation coefficient was $R=0.262$ at the level of $\alpha \leq 0.05$ and the coefficient of $\mathrm{R}^{2}=0.069$, i.e. $6.9 \%$ of the changes in the human resources performance due to the change in the level of attention to organizational requirements, and the degree of impact of organizational requirements $\beta=0.262$ This means that the increase of one degree in the level of attention to organizational requirements leads to an increase in the improvement of the performance of human resources by $26.2 \%$ and confirms the significance of this impact calculated $F$ value which amounted to 5.161, which is significant at the level of $\alpha \leq 0.05$ and the value of calculated $T$ at 2.272, which reached a function at the level $\alpha \leq 0.05$ and confirms that the fourth sub-hypothesis is incorrect.

\section{The decision :-}

Rejecting the null hypothesis and accepting the alternative hypothesis.

\section{RESULT OF THE FIRST HYPOTHESIS TEST}

Rejecting the main hypothesis and its sub-hypotheses in their nihilistic form, and accepting the alternative hypothesis which states that there is a statistically significant impact at the level of $\alpha \leq 0.05$ for the health information systems (hardware, software, human and organizational requirements) on the performance of human resources at King Faisal Specialist Hospital in Taif.

\section{The second main hypothesis : -}

There are no statistically significant differences at the level of $\alpha \leq 0.05$ for health information systems in improving the performance of human resources at King Faisal Specialist Hospital in Taif Governorate due to personal and professional variables.

\section{The First-sub Hypothesis :-}

There are no statistically significant differences at the level of $\alpha \leq 0.05$ for health information systems in improving the performance of human resources in King Faisal Specialist Hospital in Taif Governorate due to the age variable.

To test this sub-hypothesis, one way ANOVA was used to test each sub-hypothesis as follows. 
Table (14) : The mean and the standard deviation of the impact of health information systems on the performance of resources according to the age variable

\begin{tabular}{||c|c|c|c|c|c|c|c||}
\hline \multicolumn{2}{|c|}{30 Year or less } & \multicolumn{2}{c|}{$31-40$ year } & \multicolumn{2}{c|}{$41-50$ year } & \multicolumn{2}{c|}{51 and above } \\
\hline Mean & St. Dev. & Mean & St. Dev. & Mean & St. Dev. & Mean & St. Dev. \\
\hline \hline 7.638 & 0.587 & 7.861 & 0.879 & 8.331 & 0.687 & 8.071 & 0.768 \\
\hline
\end{tabular}

The above table shows that the highest statistical averages were in the age category $(41-50)$. To determine the significance of the differences according to the age variable, one way ANOVA was performed and the following table shows this.

Table (15): The results of ANOVA

\begin{tabular}{||l|c|c|c|c|c|c||}
\hline \hline & Sum of Squares & Mean Square & df & F & Sig. & Decision \\
\hline \hline Between Groups & 4.56 & 1.52 & 3 & & & \multirow{2}{*}{$\begin{array}{c}\text { Accept } \\
\text { Hypothesis }\end{array}$} \\
\hline Within Groups & 37.78 & 0.555 & 68 & 2.737 & 0.05 & 71 \\
\hline Total & 42.33 & & & & \\
\hline
\end{tabular}

In the above table, there was no statistical significance for the impact of health information systems on the performance of human resources according to the age variable at the level of significance $\alpha \leq 0.05$ where the value of calculated $\mathrm{F}$ is 2.732 , which is not significant compared with the value of the periodic value of (1.667).

\section{The decision :-}

Accepting the nihilistic hypothesis in its current form.

\section{The Second-sub Hypothesis :-}

There are no statistically significant differences at the level of $\alpha \leq 0.05$ for health information systems in improving the performance of human resources in King Faisal Specialist Hospital in Taif Governorate due to the variable of qualification.

Table (16) : The mean average and the standard deviation of the impact of health information systems on performance according to the variable of qualification

\begin{tabular}{||c|c|c|c|c|c|c|c||}
\hline \hline \multicolumn{2}{|c|}{ Less Than General Secondary } & \multicolumn{2}{|c|}{$31-40$ year } & \multicolumn{2}{c|}{$41-50$ year } & \multicolumn{2}{c|}{51 and above } \\
\hline \hline Mean & St. Dev. & Mean & St. Dev. & Mean & St. Dev. & Mean & St. Dev. \\
\hline \hline 7.333 & 0.629 & 8.421 & 0.624 & 8.011 & 0.823 & 7.875 & 0.582 \\
\hline
\end{tabular}

The above table shows that the highest means were in favor of the holders of the bachelor's degree qualification. To find out the significance of the differences according to the qualification variable, the One Way ANOVA test was performed and the following table shows this.

Table (17) : The results of ANOVA

\begin{tabular}{|l|c|c|c|c|c|c||}
\hline & Sum of Squares & Mean Square & df & F & Sig. & Decision \\
\hline \hline Between Groups & 4.413 & 1.471 & 3 & & & \multirow{2}{*}{ Accept } \\
Within Groups & 37.92 & 0.558 & 68 & 2.638 & 0.057 & Hypothesis \\
\hline Total & 42.33 & & 71 & & & \\
\hline
\end{tabular}

In the previous table, there were no statistically significant differences on the impact of health information systems on the performance of human resources according to the variable of the qualification at the level of significance $\alpha \leq 0.05$ where the value of $F$ calculated at 2.638 is not significant compared with the value of the periodic value of (1.667). 


\section{The decision :-}

Accepting the nihilistic hypothesis in its current form.

\section{The Third-sub Hypothesis :-}

There are no statistically significant differences at the level of $\alpha \leq 0.05$ for health information systems in improving the performance of human resources in King Faisal Specialist Hospital in Taif Governorate due to the variable of professional experience.

Table (18) : The mean and the standard deviation of the impact of health information systems on performance according to the variable of professional experience

\begin{tabular}{||c|c|c|c|c|c|c|c||}
\hline \hline \multicolumn{2}{|c|}{5 Years or less } & \multicolumn{2}{c|}{$6-10$ Years } & \multicolumn{2}{c|}{$11-15$ Years } & \multicolumn{2}{c|}{ More than 16} \\
\hline mean & $\begin{array}{c}\text { Standard } \\
\text { Deviation }\end{array}$ & mean & $\begin{array}{c}\text { Standard } \\
\text { Deviation }\end{array}$ & mean & $\begin{array}{c}\text { Standard } \\
\text { Deviation }\end{array}$ & mean & $\begin{array}{c}\text { Standard } \\
\text { Deviation }\end{array}$ \\
\hline \hline 7.821 & 0.572 & 8.125 & 0.659 & 8.333 & 0.862 & 7.941 & 0.922 \\
\hline
\end{tabular}

The above table shows that the highest means were in the professional experience category (11 - 15 years). To find out the significance of the differences according to the professional experience, the one way ANOVA was performed and the following table shows this.

Table (19) : The results of ANOVA

\begin{tabular}{|c|c|c|c|c|c|c|}
\hline & $\begin{array}{c}\text { Sum of } \\
\text { Squares }\end{array}$ & Mean Square & df & $\mathbf{F}$ & Sig. & Decision \\
\hline Between Groups & 1.71 & 0.570 & 3 & \multirow{3}{*}{3.955} & \multirow{3}{*}{0.419} & \multirow{3}{*}{$\begin{array}{c}\text { Accept } \\
\text { Hypothesis }\end{array}$} \\
\hline Within Groups & 40.62 & 0.597 & 68 & & & \\
\hline Total & 42.33 & & 71 & & & \\
\hline
\end{tabular}

In the previous table, there are no statistically significant differences on the impact of health information systems on the performance of human resources according to the professional experience at the level of significance $\alpha \leq 0.05$ where the value of $\mathrm{F}$ calculated at 3.955 is not significant compared to the value of the periodic value of (1.667).

\section{The decision :-}

Accepting the nihilistic hypothesis in its current form.

\section{The decision :-}

\section{RESULT OF THE SECOND MAIN HYPOTHESIS TEST}

Accepting of the second main hypothesis and its sub-hypotheses in their current nihilistic form. This indicates that there is no statistically significant effect at the level of $\alpha \leq 0.05$ for health information systems in improving the performance of human resources in King Faisal Specialist Hospital in Taif Governorate due to personal and professional variables (age, qualification and professional experience).

\section{RESULTS}

1. The respondents' perceptions of the requirements of health information systems were high.

2. The respondents' perceptions of human resources performance were high.

3. There is an impact of the requirements of health information systems (hardware, software, human and organizational) on the performance of human resources.

4. There are no statistically significant differences between the respondents' perceptions due to variables (age, qualification and professional experience). 


\section{RECOMMENDATIONS :-}

1. Activating the concept of human relations between senior departments and employees in order to enhance the motivation of employees and improve their performance.

2. Assigning the right man in the right place in proportion to their abilities and academic qualifications which increases their acceptance of work and thus improving performance and not overburdening them with work beyond their capabilities and the time required to achieve.

3. Increasing the support of the senior management of users of the system and exploring their views on the problems they face until they are overcome.

4. Providing software that is compatible with the devices and networks used in the work.

\section{References : -}

Misleh, Attia: Measuring the quality of services from the point of view of workers and patients in hospitals. Amman, 2012.

Al-Qurashi, Najwan: The Impact of Computerized Management Information Systems on Job Performance - A Field Study on Wai Mobile Workers. Master Thesis published, Faculty of Administrative Sciences, Aden, Yemen, 2007.

Jabr, Abdul Rahman: Administrative Creativity and its Impact on Job Performance - An Empirical Study on UNRWA Schools in Gaza Strip, Unpublished Master Thesis, Islamic University, Gaza, 2010.

Al-Qaryuti, Mohamed Qassem: Organizational behavior. $4^{\text {th }}$ ed., Dar Al Shorouk for Publishing and Distribution, Amman, Jordan, 2003.

Sultan, Mohammed Said Anwar: Organizational behavior. New University House, Alexandria, 2004.

Hassan, Rawia: Human Resources Management. University House for Collection, Publishing and Distribution, Alexandria, 2000.

Shourbagi, Naguib: Regional Office for the Eastern Mediterranean to support e-health in the region. World Health Organization, Regional Office for the Eastern Mediterranean, Cairo, 2007.

Dweik, Masbah Abdulhadi: The implications of the use of computerized health information systems on the decision-making process in the Gaza State Hospital. Master Thesis, Business Administration, Islamic University, Gaza, 2010.

Najjar, Farid: Hospital Management and Pharmaceutical Companies - Integration of Treatment and Medicine Directory of Ministers of Health and Directors of Hospitals and Pharmaceutical Companies." University House, Alexandria, 2007.

Alarabi, Attia: The Impact of Information Technology on the Performance of Human Resources in Local Government Bodies - A Field Study, University of Ouargla, Algeria, Faculty of Economic Sciences, Journal of the Researcher, No. 10, 2012.

Al-Gharabawi, Mahmmod: Computerized Health Information Systems and their Relation to Job Performance - A Field Study on UNRWA Relief Centers, Master Thesis, Business Administration, Al-Azhar University, Gaza, 2014

Al-Awadhi, Raafat: "The role of health information systems in the development of the abilities of employees in public hospitals in the Gaza Strip." Arab College of Technical Sciences, published paper, Al-Quds Open University, Palestine, 2013.

Wager, K., Lee, F., Glaser, J. (2005). "Managing health care information systems", John Wiley \& Sons, Inc., San Francisco, CA, USA. Malherbe.

Sakaran, Uma , (2010). Research Method for Buildings, A skill buildings approach. 4th ed. N.Y, John Willy \& Sons, Inc.

WHO. (2009). Health Metrics Network, framework \& standards for the Development of country health information systems. 1st. WHO, Geneva.

Schoen, C., and Apple Baum, S. (2012). "A Survey of Primary Care Doctors in Ten Countries Shows Progress in Use of Health Information Technology, Less In other Areas", Health Affairs Web First, published online Nov. 15.

WHO. (2000). "A selection of important health indicators", World Health Organization, Manila, Philippines. 
Robbins, j., \& Wireman, M., (2008). A resource Based Approach to Multi business firm: Empirical Analysis of portfolio Inter Relationships \& Corporate Financial performance." Strategic Management Journal, Vol., No. 1.

Daft, R, L, (2011). Theory and Design. 4th. west Publishing co., USA.

Marques, A., and Martins, M. (2011). "Medical Records System Adoption in European Hospitals", the Electronic Journal Information Systems Evaluation Vol. 14, No. 1.

Al-Yaseen, H., and Salem, M. (2010). "Post-Implementation Evaluation of HealthCare Information Systems in Developing Countries", Electronic Journal Information Systems Evaluation, Vol. 13, No. 1. 